\title{
Ongoing Challenges in the Endoscopic Management of Hilar Cholangiocarcinoma
}

\author{
Harry R. Aslanian • Priya A. Jamidar
}

Published online: 11 March 2011

(C) Springer Science+Business Media, LLC 2011

The majority of patients with cholangiocarcinoma present with locally unresectable disease and the median survival with radiation and chemotherapy is $7-12$ months. The endoscopic palliation of inoperable hilar cholangiocarcinoma remains one of the more challenging cases for the biliary endoscopist. The endoscopist must define the anatomy without injecting contrast into ducts that will not be drained, achieve guide-wire access for unilateral or bilateral stent placement and determine what type of stent-plastic or self-expanding metal (SEMS), will best serve the patient to relieve pain and jaundice and prevent cholangitis.

Raju et al. [1] present a retrospective review of 100 patients who underwent endoscopic plastic or SEMS placement for inoperable hilar cholangiocarcinoma. Patients were regularly followed to death or reintervention, and stent patency and survival were examined. In 48 patients uncovered (as expected due to the hilar location of obstruction) SEMS were placed, with plastic stents (at least one of which was 10 French) in the other 52 patients. The Bismuth Classification of lesions was similar between the groups. There was however, a greater number of Type 3 and 4 cases that received plastic stents $(73.1 \%$ vs. $56.3 \%)$, potentially favoring a better outcome with SEMS. The technical success rate was high in both groups (95.8\% vs. 94.2\%). Bilateral stenting was performed successfully in 20/23 plastic stent patients and 5/5 SEMS. The SEMS group demonstrated significantly better stent patency (5.56 vs. 1.86 months) and required fewer re-interventions for stent obstruction ( $1.53 \mathrm{vs}$.

H. R. Aslanian $(\bowtie) \cdot$ P. A. Jamidar

Department of Internal Medicine, Section of Digestive Diseases,

Yale University, New Haven, CT, USA

e-mail: harry.aslanian@yale.edu
4.6). The complication rate was similar in both groups $(8.3 \%$ SEMS and $7.7 \%$ plastic) and there was a non-significant trend towards greater survival in the SEMS group (9.08 vs. 8.22 months). During the study time period, routine stent changes in patients with plastic stents were not performed; however, the median patency was only 1.5 months. No difference between the patency of straight and pigtail plastic stents was seen, nor was there a difference between unilateral and bilateral plastic stents or SEMS. All re-interventions were performed endoscopically, nine patients with plastic stents were converted to SEMS and plastic stents were placed within SEMS in four patients.

The results of Raju et al. are similar to those of prior studies identifying less stent failure with the use of SEMS versus plastic stents for hilar tumors [2, 3]. There is scant information in the way of randomized comparisons between plastic and metal stents. A study by Wagner et al. [2] is the only prospective, randomized study. Twenty patients were randomized between metal stents placed percutaneously or endoscopic stents placed by a combination of endoscopic-percutaneous technique. Perdue et al. [3] reviewed a multicenter database of 62 consecutivelyreported endoscopically-placed metal or plastic stents for hilar obstruction. Outcomes in favor of metals stents were reported in both studies.

The benefit of bilateral versus unilateral stenting continues to be debated [4, 5]. Injection of contrast into intrahepatic ducts which can not be adequately drained should be avoided as this is associated with worse outcomes [6]. MRCP has been advocated to assist in providing a guide to the ductal anatomy and formulating a plan for drainage [7]. Approximately one-fourth to one-third of the liver needs to be drained to relieve jaundice [8]. Raju et al. found no difference in patency between bilateral and unilateral stenting. 
A study of bilateral versus unilateral SEMS found greater patency with bilateral SEMS [9]. The recent availability of smaller SEMS delivery systems allows sideby side pre-deployment insertion of bilateral SEMS; however, this procedure remains technically challenging even for experienced biliary endoscopists. Furthermore, SEMS placed in a side-by-side configuration require approximation of the distal portion of the stents to allow future endoscopic access to the proximal bile ducts.

SEMS can be divided between closed and open cell based on the shape and size of the openings created by the mesh pattern. The most popular technique for bilateral SEMS placement is to place a wide mesh SEMS into one side with a second SEMS into the contralateral side across the mesh [10]. This approach also has the advantage of being easy to cannulate during reintervention (one stent lumen instead of two side-by-side). The closed cell configuration of the Wallstent (Boston Scientific, Natick, Massachusetts) utilized in the study of Raju et al. makes this technique more difficult to perform. Recent trials of SEMS with extra-wide open mesh designs in the central portion to facilitate bilateral SEMS placement have shown encouraging results $[11,12]$.

The cause of death in the study by Raju et al. was not specifically outlined; however, it was felt to be due to disease progression rather than cholangitis. More effective therapies for locally advanced cholangiocarcinoma are needed. Initial studies of photodynamic therapy (PDT) have been encouraging [13-15]. A randomized trial of stenting versus stenting plus PDT identified greater survival in the PDT group [16]. PDT may be performed with plastic stent insertion or possibly within SEMS. Additionally, future development of drug-eluting SEMS [17] may add to the palliation and treatment options offered by the biliary endoscopist.

The limited data available appears to support using self expanding metal stents over plastic stents for the palliation of hilar cholangiocarcinoma. There are many remaining unanswered questions and prospective data is sorely lacking. It is unclear for example if bilateral stenting provides better palliation than unilateral stenting. The optimal technique of bilateral stenting has yet to be defined, i.e., whether side-by-side stenting is preferable to placing a second stent across the mesh of the first stent (Y-configuration stenting) and when closed cell vs open cell mesh configuration stents should be utilized. Clearly, further developments and refinements in stent design as well as randomized prospective studies are much needed.

\section{References}

1. Raju RP, Jaganmohan SR, Ross WA, et al. Optimum palliation of inoperable hilar cholangiocarcinoma: comparative assessment of the efficacy of plastic and self-expanding metal stents. Dig Dis Sci. 2011 (Epub ahead of print). doi:10.1007/s10620-010-1550-5.

2. Wagner HJ, Knyrim K, Vakil N, Klose KJ. Plastic endoprostheses versus metal stents in the palliative treatment of malignant hilar biliary obstruction. A prospective and randomized trial. Endoscopy. 1993;25:213-218.

3. Perdue DG, Freeman ML, DiSario JA, et al. Plastic versus selfexpanding metallic stents for malignant hilar biliary obstruction: a prospective multicenter observational cohort study. J Clin Gastroenterol. 2008;42:1040-1046.

4. Deviere J, Baize M, de Toeuf J, Cremer M. Long-term follow-up of patients with hilar malignant stricture treated by endoscopic internal biliary drainage. Gastrointest Endosc. 1988;34:95-101.

5. De Palma GD, Galloro G, Siciliano S, et al. Unilateral versus bilateral endoscopic hepatic duct drainage in patients with malignant hilar biliary obstruction: results of a prospective, randomized, and controlled study. Gastrointest Endosc. 2001;53: 547-553.

6. Chang WH, Kortan P, Haber G. Outcome in patients with bifurcation tumors who undergo unilateral versus bilateral hepatic duct drainage. Gastrointest Endosc. 1998;47:354-362.

7. Dowsett Hintze RE, Abou-Rebyeh H, Adler A, et al. Magnetic resonance cholangiopancreatography-guided unilateral endoscopic stent placement for Klatskin tumors. Gastrointest Endosc. 2001;53:40-46.

8. Dowsett JF, Vaira D, Hatfield AR, et al. Endoscopic biliary therapy using the combined percutaneous and endoscopic technique. Gastroenterology. 1989;96:1180-1186.

9. Naitoh I, Ohara H, Nakazawa T, et al. Unilateral versus bilateral endoscopic metal stenting for malignant hilar biliary obstruction. J Gastroenterol Hepatol. 2009;24:552-557.

10. Chahal P, Baron TH. Expandable metal stents for endoscopic bilateral stent-within-stent placement for malignant hilar biliary obstruction. Gastrointest Endosc. 2010;71:195-199.

11. Park DH, Lee SS, Moon JH, et al. Newly designed stent for endoscopic bilateral stent-in-stent placement of metallic stents in patients with malignant hilar biliary strictures: multicenter prospective feasibility study. Gastrointest Endosc. 2009;69: $1357-1360$.

12. Kim JW, Kang DH, Kim HW, et al. Usefulness of slimmer and open-cell-design stents for endoscopic bilateral stenting and endoscopic revision in patients with hilar choangiocarcinoma. Gastrointest Endosc. 2009;70:1109-1115.

13. Rumalla A, Baron TH, Wang KK, et al. Endoscopic application of photo-dynamic therapy for cholangiocarcinoma. Gastrointest Endosc. 2001;53:500-504.

14. Shim CS, Cheon YK, Cha SW, et al. Prospective study of the effectiveness of percutaneous transhepatic photodynamic therapy for advanced bile duct cancer and the role of intraductal ultrasonography in response assessment. Endoscopy. 2005;37:425433.

15. Kahaleh M, Mishra R, Shami V, et al. Unresectable cholangiocarcinoma: comparison of survival in biliary stenting alone versus stenting with photodynamic therapy. Clin Gastroenterol Hepatol. 2008;6:290-297.

16. Ortner ME, Caca K, Berr F, et al. Successful photodynamic therapy for nonresectable cholangiocarcinoma: a randomized prospective study. Gastroenterology. 2003;125:1355-1363.

17. Suk KT, Kim JW, Kim HS, et al. Human application of a metallic stent covered with a paclitaxel-incorporated membrane for malignant biliary obstruction: multicenter pilot study. Gastrointest Endosc. 2007;66:798-803. 